Neal L. Thomson

\title{
Address of the Congress President
}

The Australian section of the Société Internationale de Chirurgie Orthopédique et de Traumatologie has worked for many years to construct a scientific and social program that we present to you at SICOT 99 Sydney, incorporating SIROT (Société Internationale de Recherché Orthopédique et de Traumatologie).

We consider we have brought together a representative spectrum of world orthopaedics in Sydney. Opportunity has been given for both young and old orthopaedic surgeons to present their new developments and pass on their experiences to attendees from the 103 member countries of SICOT and to surgeons from all areas of the globe. SICOT is an opportunity to meet and exchange ideas between surgeons from all continents and all races. $\mathrm{We}$, as a committee, wish you welcome in Sydney and Australia and ask you to take part in this educational and social experience.

As your Congress President, I have been privileged to visit many countries I may not have had the opportunity to visit over the past 5 or 6 years. Our travels in promoting SICOT 99 Sydney have taken us to all continents on the globe, except for South America. My wife, Jan, and I have met many new acquaintances and experienced open hospitality in all the cities we visited. New friends and friendships have been made and will remain lifelong memories. We wish we could repay all the hospitality during your stay in Sydney. Unfortunately, we will not have time to acquaint you with our home or our city: but should you return to Sydney following the Congress, we would welcome you again and hopefully be able to continue our friendship.

To all attendees I can only say that involvement in the SICOT family of Orthopaedic Surgeons and Traumatologists can be both a rewarding experience and an educational travelogue that should not be missed. No one individual can maintain a constant input of scientific education that cannot be expanded. The contact and international experience will not be gained in any other Con-

N.L. Thomson $(\bullet)$

Specialist Medical Centre, Room 203, Arcade 83,

79-83 Longueville Road, Lane Cove, NSW 2066, Australia gress as individuals gather from all areas of the world for the SICOT World Congress. I encourage the young orthopaedists to become members of the Society and experience, as I have, a broadening of attitude and an understanding of races and people. Australia is a continental island without borders to other nations. It will amaze you to realise that we have over 230 nationalities resident within Australia. We have been labeled by some as unfeeling to other races. This is far from the truth. In fact, we wish, like all nationalities to have our own national identity, but welcome influences and change that can improve and foster harmony and understanding between races and nationalities.

As members of SICOT you will find an understanding among its members that allows one to comment about ideals and to learn by association. The occasion of a World Congress of a Society, born in 1929 and now passing into the new millennium, is an important time in the orthopaedic calendar. The contributions to the organisation of the Congress must change with the next millenni-

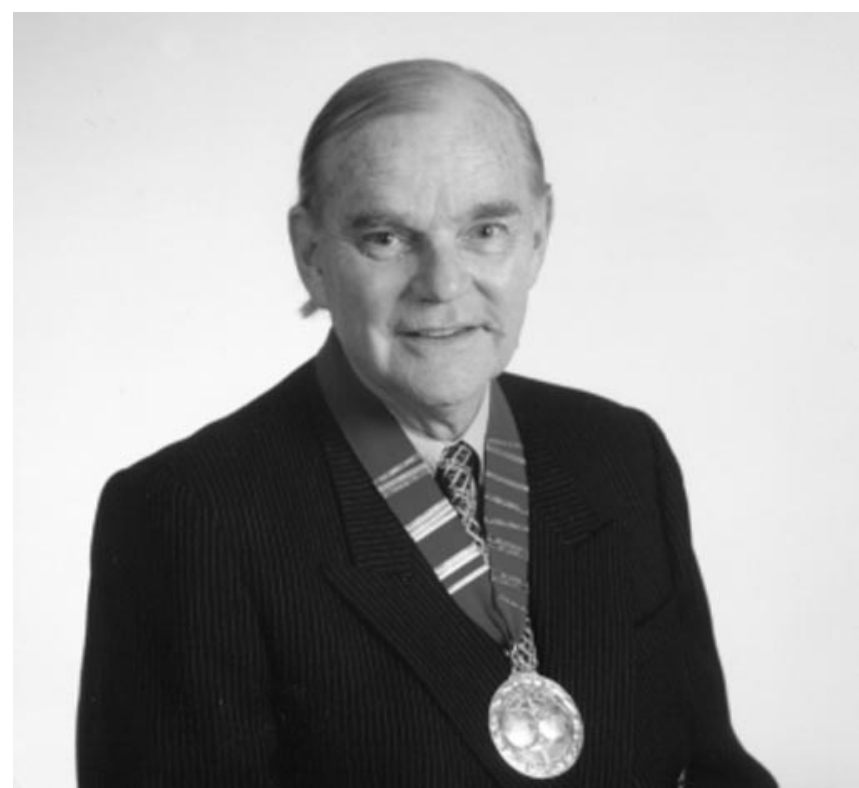


um, because there are ever increasing challenges from the other orthopaedic bodies wishing to in-road into our activities. The Scientific Committee must be pro-active in developing a database of world speakers on their specific areas of interest. Speakers that have already indicated that they are willing to contribute to the Congress. This would enhance the scientific quality of the Congress. National delegates must play an ever increasing role in the dissemination of material advertising the Congress. The need for worldwide distribution of the first announcement, call for abstracts and final call for registration should be developed on an active network involving the National Delegates. As the only truly global Society we must develop a global distribution of material.
Guidelines for abstract submission need to be drawn up so that there is no confusion about the number of papers that can be presented by one surgeon and the cut-off time for replying to an offer of acceptance of an abstract. We have, in the organisation of the Congress, had many problems caused by individuals changing their addresses, fax and phone and being impossible to contact and many people failing to follow the instructions clearly marked on abstract forms and/or in letters.

As the next triennium approaches there are many challenges to accomplish to meet the goals of the truly representative and highly educational World Congress. I wish the next Organising Committee every success in the organisation of their Congress. 